\title{
Improving nomenclatural consistency: a decade of experience in the World Register of Marine Species
}

\author{
Tammy HORTON ${ }^{1, *}$, Serge GOFAS ${ }^{2}$, Andreas $\mathrm{KROH}^{3}$, Gary C.B. POORE ${ }^{4}$, \\ Geoffrey READ ${ }^{5}$, Gary ROSENBERG ${ }^{6}$, Sabine STÖHR ${ }^{7}$, Nicolas BAILLY ${ }^{8}$, \\ Nicole BOURY-ESNAULT ${ }^{9}$, Simone N. BRANDÃO ${ }^{10}$, Mark J. COSTELLO ${ }^{11}$, \\ Wim DECOCK $^{12}$, Stefanie DEKEYZER ${ }^{13}$, Francisco HERNANDEZ ${ }^{14}$, Jan MEES ${ }^{15}$, \\ Gustav PAULAY ${ }^{16}$, Leen VANDEPITTE ${ }^{17}$, Bart VANHOORNE ${ }^{18} \&$ Sofie VRANKEN ${ }^{19}$ \\ ${ }^{1}$ National Oceanography Centre, European Way, Southampton SO14 3ZH, UK. \\ ${ }^{2}$ Departamento de Biología Animal, University of Málaga, Faculty of Sciences, \\ Campus de Teatinos, 29071 Málaga, Spain. \\ ${ }^{3}$ Natural History Museum Vienna, Department of Geology and Palaeontology, \\ Burgring 7, 1010 Vienna, Austria. \\ ${ }^{4}$ Museums Victoria, GPO Box 666, Melbourne, Vic. 3001, Australia. \\ ${ }^{5}$ National Institute of Water \& Atmosphere (NIWA), 301 Evans Bay Parade, \\ Greta Point, Wellington, New Zealand. \\ ${ }^{6}$ Academy of Natural Sciences, Drexel University, 1900 Benjamin Franklin Parkway, \\ Philadelphia, PA 19103-1195, USA. \\ ${ }^{7}$ Swedish Museum of Natural History, Dept. of Zoology, Box 50007, SE-10405 Stockholm, Sweden. \\ ${ }^{8}$ FishBase Information and Research Group (FIN), c/o IRRI, Khush Hall, \\ Los Baños, Laguna 4031, Philippines.
}

${ }^{8}$ Hellenic Centre for Marine Research, Gournes Pediados, P.C. 71500, Gouves, Heraklion, Crete, Greece.

${ }^{9}$ Institut méditerranéen de Biodiversité et d'Écologie marine et continentale, UMR 7263

CNRS, IRD, Aix-Marseille University, Station Marine d'Endoume, rue Batterie des Lions, Marseille 13007, France.

${ }^{10}$ Programa de Pós-Graduação em Sistemática e Evolução, Laboratório de Geologia e Geofísica

Marinha e Monitoramento Ambiental, Universidade Federal do Rio Grande do Norte,

Campus Universitário Lagoa Nova, CEP 59072-970 - Natal, RN - Brazil.

${ }^{11}$ Institute of Marine Science, University of Auckland, P. Bag 92019, Auckland 1142, New Zealand. 12,13,14,15,17,18,19 Flanders Marine Institute (VLIZ) - InnovOcean Site - Wandelaarkaai 7, 8400,

Oostende, Belgium.

${ }^{16}$ Florida Museum of Natural History, Gainesville, Florida, 32611-2710, USA.

*Corresponding author: tammy.horton@noc.ac.uk

2Email: sgofas@uma.es

${ }^{3}$ Email: andreas.kroh@nhm-wien.ac.at

${ }^{4}$ Email: gpoore@museum.vic.gov.au

5Email: Geoffrey.Read@niwa.co.nz

${ }^{6}$ Email: rosenberg.ansp@drexel.edu

${ }^{7}$ Email: sabine.stohr@nrm.se 

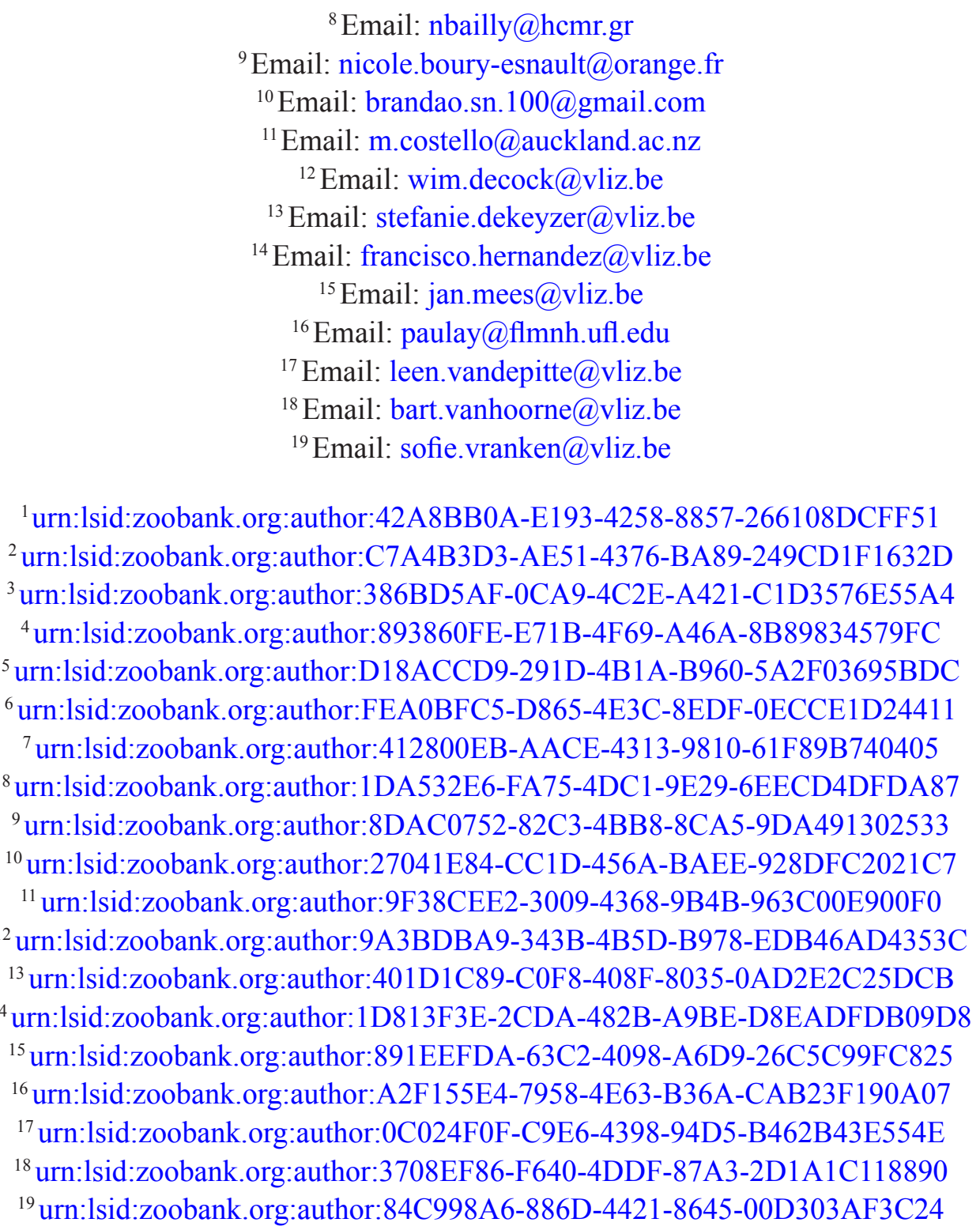

\begin{abstract}
The World Register of Marine species (WoRMS) has been established for a decade. The early history of the database involved compilation of existing global and regional species registers. This aggregation, combined with changes to data types and the changing needs of WoRMS users, has resulted in an evolution of data-entry consistency over time. With the task of aggregating the accepted species names for all marine species approaching completion, our focus has shifted to improving the consistency and quality of data held while keeping pace with the addition of $>2000$ new marine species described annually. This paper defines priorities and longer-term aims that promote standardisation within and interoperability among biodiversity databases, provides editors with further information on how to input nomenclatural data in a standardised way and clarifies for users of WoRMS how and why names are represented as they are. We 1) explain the categories of names included;2) list standard reasons used to explain why a name is considered 'unaccepted' or 'uncertain'; 3) present and explain the more difficult situations encountered; 4) describe categories of sources and notes linked to a taxon; and 5) recommend how type material, type locality and environmental information should be entered.
\end{abstract}

Keywords. World Register of Marine Species, WoRMS, taxonomic databases, taxonomy, nomenclature. 
Horton T., Gofas S., Kroh A., Poore G.C.B., Read G., Rosenberg G., Stöhr S., Bailly N., Boury-Esnault N., Brandão S.N., Costello M.J., Decock W., Dekeyzer N., Hernandez F., Mees J., Paulay G., Vandepitte L., Vanhoorne B. \& Vranken S. 2017. Improving nomenclatural consistency: a decade of experience in the World Register of Marine Species. European Journal of Taxonomy 389: 1-24. https://doi.org/10.5852/ejt.2017.389

\section{Introduction}

The World Register of Marine Species (WoRMS) is a biodiversity information system designed as a global open-access inventory of the names of marine taxa. WoRMS was established ten years ago, in 2007, and has been growing in both content and popularity ever since (Costello et al. 2013). WoRMS currently contains 613499 taxon names (from infraspecies to kingdom), 479092 of which are species names and 243081 are accepted marine species names (data accessed 18 Dec. 2017). These names are entered, edited and revised as necessary by 278 current voluntary taxonomic editors (WoRMS Editorial Board, see Horton et al. 2017). The database is hosted on a MS SQL database platform known as Aphia (Vandepitte et al. 2015). A regularly updated technical Aphia manual is openly available to editors and users on the WoRMS website (http://www.marinespecies.org/aphia.php?p=manual).

The WoRMS database was inaugurated in 2008, but was actually established as a project in late 2007 (Appeltans et al. 2008, 2011; Vandepitte et al. 2015). At the beginning, in order to facilitate the creation of a useful resource, and to ensure that taxonomist experts were not asked to repeat the work of collating information, a number of already existing species registers were incorporated into WoRMS (Costello et al. 2013). These included six all-taxon marine species lists at the regional level (e.g., the European Register of Marine Species, ERMS (Costello et al. 2000); Register of Antarctic Marine Species, RAMS (De Broyer et al. 2017)), and 14 global species databases covering entire taxonomic groups at a global level (e.g., World list of Marine, Freshwater and Terrestrial Crustacea Isopoda (Boyko et al. 2017), World list of Ophiuroidea (Stöhr et al. 2017)). The Aphia database also holds numerous non-marine taxa as part of Global Species Databases, for those taxa also found in freshwater and/or terrestrial environments, and some orphaned non-marine taxon datasets, although these are not visible through the WoRMS portal by default (Costello et al. 2013; Vandepitte et al. 2015). At the time of the inauguration in 2008, a press release highlighted that there were already 122500 accepted marine species names in WoRMS, and the 137 taxonomic experts involved at the time estimated that there were about 230000 marine species known to science (Census / WoRMS News Release 2008). By 2012, after five years of progress, WoRMS contained 460000 taxon names (from infraspecies to kingdom), of which 368000 were species names, of which 215000 were accepted (Costello et al. 2013). The original estimate of 230000 accepted marine species was reached on 15 July 2015. With the task of aggregating the accepted species names for all marine species approaching completion, a list of new priorities was drawn up by the Steering Committee (a group of 12 editors elected for three-year terms to govern current and future development of WoRMS, http://www.marinespecies.org/about.php\#governance). These priorities focus on improving the consistency and quality of the data already held for each species whilst also keeping the database up-todate with the addition of ca 2000 new marine species described annually.

The aggregation of global and regional datasets into WoRMS, and the revisionary efforts of over 300 voluntary expert taxonomists over the last decade, have resulted in slightly diverging current editorial practices between taxa. This can influence management of the database and data use in the future. While new taxonomic editors are provided with access to a technical training manual on the process of editing WoRMS, there has not been, until now, any guidance on the best practice for entering and editing taxonomic names in WoRMS. In order to provide a standard set of procedures for the most commonly encountered situations in WoRMS, the Steering Committee decided that a guidance document should be written for use by the editors, illustrated by examples of best practice where possible. It was anticipated that this guidance document should promote consistency between the application of the International 
Code of Zoological Nomenclature (ICZN) and the International Code of Nomenclature for algae, fungi, and plants (ICN, McNeill et al. 2012), and in the addition and editing of names in WoRMS. By publishing a version of this guidance, we aim to make WoRMS' methodology available to other taxonomic name databases and WoRMS users, to further promote consistency, and to thus facilitate the use of WoRMS data in downstream analyses.

Users of taxonomic information are faced with numerous challenges in navigating taxonomic databases, including WoRMS. These challenges include determining how taxonomic issues such as misspellings of names, misapplications of taxon concepts, synonymisations and name recombinations are represented in a taxonomic name database. These concepts were discussed in detail by Costello et al. (2013). We make use of nomenclatural terms already covered extensively by Hawksworth (2010) and refer to information and discussions in the comprehensive guidelines prepared by Welter-Schultes (2012) for the GBIF database. Although we refer specifically to the use of these terms and methods in relation to editing of the WoRMS database, it is anticipated that the examples and recommendations for consistency presented here will be applied by other database managers, users and custodians of collections using WoRMS.

\section{Rationale and application of the World Register of Marine Species}

The aim of WoRMS is to provide an authoritative and comprehensive list of names of marine organisms arranged in the most up-to-date and stable hierarchy as determined by the appropriate editor. The WoRMS hierarchy incorporates, without necessarily being driven by, the very latest phylogeny such as in the Tree of Life (www.tolweb.org), but attempts to reflect a stable and practical classification. 'Match Taxa', an online service on the WoRMS website furthermore allows to upload taxon lists and retrieve the most-up-to-date names and classifications for these taxa.

The primary goals of WoRMS are:

\section{(1) To promote consistency and stability of names}

This upholds the goal stated in the preamble of the ICZN "to promote stability and universality in the scientific names of animals and to ensure that the name of each taxon is unique and distinct". Consistency and stability are of particular concern in the case of species important to society, be they of commercial or medical use, harmful to humans or endangered species listed in legal texts (Garnett \& Christidis 2017). Since the launch and development of WoRMS, the accuracy of names used in non-taxonomic works has significantly improved. For example, prior to 2007 the Manila clam Ruditapes philippinarum (Adams \& Reeve, 1845), a commercially important species farmed and introduced in many parts of the world, was recorded as Ruditapes philippinarum in the title of 1270 publications listed in Google Scholar, and in 87 further publications (6.4\%) with the invalid synonym Ruditapes semidecussatus (Reeve, 1864). In contrast, for the period 2007-2017, the species name philippinarum was used in 1040 titles and semidecussatus was not used in any article title.

\section{(2) To serve as a guide to interpret the taxonomic literature}

The original primary goal of WoRMS was to collate a list of accepted species names, but also to include important synonyms. Including information on unaccepted names (synonyms, misspellings, old combinations etc.) and linking these to the accepted name provides the user with an interpretation of the taxonomic history of a species and some understanding of the reason(s) for non-acceptance of certain names. Resolving taxonomic issues requires informed individuals who understand the problems and how they have arisen, and who know the rules of the nomenclatural codes (Costello et al. 2013). The addition of this expert-level interpretation of the taxonomic literature is the main difference between the WoRMS database and other nomenclators that aim to serve a list of all names regardless of their taxonomic status. 
An additional priority of WoRMS is to support each name in the database with a published, citable source containing the name that is linked, whenever possible, to the publisher or journal website, portals of digitisation efforts and/or an accessible PDF. Providing these direct links to the taxonomic literature is another progressive feature of WoRMS and is much appreciated by users. Species have been described in thousands of books and journals and gathering this literature is time-consuming and difficult. Again, expert taxonomists with knowledge of the literature for their taxonomic group are in the best position to undertake this task. Parallel with the development of WoRMS, the Biodiversity Heritage Library (BHL, http://www.biodiversitylibrary.org/) and many other repositories were set up, providing free access to the full texts of most publications prior to 1921 and to some later ones. The task for taxonomic editors is to determine which work is the original description, and where appropriate, which is a source that synonymises the species, or is relevant for another reason. Important taxonomic references can therefore be linked directly to the taxon page by editors to aid interpretation of the literature by users.

\section{(3) To provide access to additional information regarding the taxon}

The minimum requirements for an entry in WoRMS is the full scientific name (i.e., combination of genus and specific epithet, author, year) placed in an accepted taxonomic hierarchy, annotated with an environment flag (e.g., marine/brackish/terrestrial/freshwater, see section on environment later) and supported by a reference. Further information is both possible and recommended to be included, and the addition of the following has been agreed by the WoRMS Steering Committee according to a priority list: original name, original description, type locality, and type species of genera. Some species pages also contain considerable additional information (e.g., type materials, distributions, feeding types, habitats) and there are plans for more. A dataset integrated with WoRMS known as Marine Species Traits (http://www.marinespecies.org/traits/about.php) has now been established and certain traits were prioritized for inclusion, namely environment, geography, depth, substratum, mobility, skeleton, diet, body size and reproduction (Costello et al. 2015).

\section{(4) To provide an estimate of the number of marine species}

The answer to the question "How many species are there on this planet?" including those species that remain to be discovered, remains disputed (Bouchet et al. 2016). The WoRMS database has been put to repeated use to make estimates of marine (and global) species numbers. These estimates commonly rely on the extrapolation of limited datasets under particular assumptions. Mora et al. (2011) based estimations of the number of global species on the Catalogue of Life (CoL, http://www.catalogueoflife.org/) and the number in the ocean on the World Register of Marine Species (WoRMS), and concluded that the number of marine species was ca 2.2 million $( \pm 0.18$ million SE), of which $91 \%$ are yet to be described. Appeltans et al. (2012) analysed data from WoRMS, used statistical models, reviewed the number of undescribed species in 100 field studies, and compiled the opinions of 122 authors to estimate "the magnitude of global marine species diversity". They concluded that fewer than 222 000-230000 marine species have already been described, predicted between one-third and two-thirds may be undescribed, and reported that fewer than one million marine species exist. Poore et al. (2014) studying bathyal fauna from Australia showed that the combination of high species richness, higher endemism than presently acknowledged, low proportions of described species, and the vast extent of unexplored bathyal and abyssal environments will lead to further accumulation of new species as more deep-sea regions are explored. They concluded that the estimates made by Appeltans et al. were too low and that all estimates of global species, however calculated, are based on limited data. A recent paper by (Costello \& Chaudhary 2017) concludes that there are likely 0.3 million species in the ocean and that two-thirds of species are now described. It is clear that the wide variation and disagreement in these estimates indicates that the actual number of marine species remains to be determined. However, the provision of 
a comprehensive global list of accepted species by WoRMS provides a basis for some species estimate methods, particularly those based on the ratio of known to unknown species in samples.

Once these goals are achieved, users can expect WoRMS to help:

- provide a currently accepted name from a list of possible alternative names in use

- check the accuracy of names used in a taxonomic listing (the online 'Match Taxa' tool automatically matches a taxon list from a spreadsheet with WoRMS (Vanhoorne et al. 2008; Vandepitte et al. 2015)

- cross-check names used elsewhere (e.g., other databases) and draw attention to mismatches. This is a two-way interaction and if names are incorrectly entered or missing in WoRMS they will be revised or added

Users of WoRMS vary from individuals to organisations engaged in various activities, which require the correct and consistent names for marine species. The WoRMS webservices are now being used by 65 organisations from 20 countries, and since permission is not required, there are likely additional users we are unaware of. Copies of the database have been licensed to 157 organisations and individuals in 33 countries and demand is growing steadily. Since 2007, all metrics on website use show a steady increase (see http://www.marinespecies.org/users.php for up-to-date figures). We have recorded 1933 publications making an explicit statement that the taxonomy is based on WoRMS or any of its subregisters (www. marinespecies.org/wormsliterature.php), and the database has been cited in the references of over 300 peer-reviewed publications since 2007.

The above goals and the many and varied uses of WoRMS all require editorial consistency according to standardised guidelines, the provision of which is the subject of this paper.

\section{Entering names in WoRMS}

WoRMS is a recording tool for published data and information. Therefore, all names entered should be based on at least one published reference source in which that particular name string (species rank and below) or rank (supraspecific names) has been used. A source should be linked to the name at the time of entry into the database and thus provides a reference to the published taxonomic literature (see section on 'Source categories'). Entries in WoRMS do not reflect unpublished taxonomic opinions nor propose new combinations for species names (for exceptions see section on 'New combination reference'). Most WoRMS taxa are governed by two nomenclatural codes; the International Code of Zoological Nomenclature (ICZN) and the International Code of Nomenclature for algae, fungi, and plants (ICN). Since 2012, WoRMS has also incorporated marine viruses following a collaboration with the International Committee on Taxonomy of Viruses (ICTV) (King et al. 2012) and holds marine bacteria according to the International Code of Nomenclature of Prokaryotes (Prokaryotic Code (2008 Revision), Parker et al. 2015). To avoid misunderstandings between their different terminologies, WoRMS uses a neutral terminology that encompasses that used in these codes. Differences are pointed out below, as necessary. The definitions provided were derived after careful consideration of nomenclatural rules. They may serve as guidance to non-taxonomists and students, beyond their application in WoRMS.

To achieve most rapidly a list of all marine species and taxa, WoRMS editors were not requested to enter original names from the outset. Nomenclators aim at recording all original names for a taxonomic group with their nomenclatural status, including the type information, but not their taxonomic status (e.g., accepted or unaccepted). Managing scientific names in a database is facilitated if original names are also recorded because all subsequent forms of the name can be linked to one objective name that will, in principle, never change (Pyle \& Michel 2008). Therefore, in 2015 an original name field was added to WoRMS, to which all subsequent names can be linked. It is now a priority for editors to enter original names in WoRMS and to link all combinations to the original name. This task is eased by existing nomenclators 
in different domains. There are multiple digital sources of names in existence (see Rees et al. 2017 for an overview and comparison of major nomenclators). In 2005, the International Commission of Zoological Nomenclature developed ZooBank as the nomenclator for groups covered by the ICZN (Polaszek et al. 2005; Pyle \& Michel 2008). ZooBank has now been defined in the ICZN as the repository of all original names published in Zoology (ICZN 2012). Additionally, since 1 January 2012, registration in ZooBank of published works containing new taxonomic names is mandatory for electronic publications and strongly recommended for paper ones, including from the legacy literature (Krell \& Pape 2015). In the future, it is anticipated that there will be progress towards the exchange of data on original names between Zoobank and WoRMS (and other databases) to avoid duplication of effort.

\section{Name status terminology}

In the published literature, it is not always clear whether a name is currently valid or not, either for nomenclatural or taxonomic reasons. In the interest of clarity and consistency, when a name is entered in WoRMS it must be given a status from a dropdown menu. The options for these in WoRMS are:

1. accepted name

2. unaccepted name

3. temporary name

4. uncertain name

5. alternate representation

\section{Accepted name}

The primary goal of WoRMS is to hold the accepted name of each marine species, because most nonspecialist users need to find the correct, current name of their taxon of interest. Accepted names are denoted by the status 'accepted' on the taxon page. This is the name considered by the editor to be the valid (zoology) or correct (plants, algae and fungi) name of the taxon. A newly published taxon is entered to WoRMS as 'accepted' (unless failing to fulfil criteria of availability (zoology) or not validly published (plants, algae and fungi)). The status of an original combination will only be changed to 'unaccepted' following publication of the name as a new combination or as a junior synonym. One or several sources should be linked to the name to support its inclusion in the database.

The accepted name is selected by the editor after consideration of the most up-to-date revision available. If contemporary works give different generic allocations or different rankings of a taxon, the editor will need to make a choice, which may not necessarily be the latest published status, but the one which he/ she considers to be the most soundly supported. This is an important point for WoRMS editors and a place where there have been differences of opinion in how best to represent the current accepted name. How should an editor decide on the accepted name? How can we provide consistency in this decision-making for the users of WoRMS? Editors may decide to represent the most up-to-date revision in WoRMS (which may not be the most authoritative), or they may choose to represent one that is perhaps a few years older, but which is considered by that editor to have stronger support. For example, a thorough revision supported by sequence data could be considered to have greater merit than a more recent revision that consists of new combinations provided in a list without discussion. An editor may therefore decide to represent the older revision as accepted. In such cases there should always be a 'taxonomic remark' note explaining the details of the case, and the opposite view should be included and be either flagged as 'unaccepted' or 'alternate representation' according to the editor's decision.

Names should be linked to their original combination (zoology) or basionym (plants, algae and fungi), i.e., the name (genus, species and subspecies) used in the original publication (and correctly spelled under ICZN or ICN rules) and which may or may not be the same as the accepted name. In WoRMS 
this is denoted the 'original name' in order to encompass and avoid conflict with the terms 'original combination' and 'basionym'.

Both accepted and original names should be added to WoRMS (as well as any superseded combinations that the editor sees fit). When a new taxon is entered and the authority is added without brackets (i.e., in its original combination), the 'original name' field does not need to be filled, as the taxon name is given this status automatically. To indicate that a combination previously added to the database is the original name, the editor can click on 'mark as original name', which is an option located after the taxon name string on each taxon page when an editor is logged in to WoRMS. Linking of non-original combinations with the original name is achieved by filling the 'original name' field on the taxon edit page (click 'edit taxon'). The original name can be selected from the list generated when the editor begins typing in this field. If the original name is not yet in WoRMS then it will need to be added before this step.

The type species of a genus should always be entered in the form of its original combination, even if it was cited in another combination at the time of designation (recommendation 67B (ICZN 1999); Article 10, Ex. 3 (ICN)).

\section{Unaccepted name}

A name that has been in use at any time but is not currently accepted. This includes names which are invalid (e.g., junior synonym, preoccupied, rejected), specific names in generic combinations which are no longer accepted, specific names written with the wrong grammatical agreement and misspellings. In WoRMS an unaccepted name must point to a currently accepted name. There are some special cases, including unavailable names, where a name does not point to a currently accepted name, e.g., some cases of nomina nuda and names that are published online only without registration in ZooBank (e.g., Goniopygus annularis Vaziri \& Arab, 2012: http://marinespecies.org/aphia.php?p=taxdetails\&id=738293). In these cases, the editor should contact the Data Management Team (DMT, info@marinespecies.org) to have the name entered without linking to an accepted name.

Unaccepted names should be linked to a published source in which the status of the name is justified. Editors should not make subjective changes on WoRMS that have not been published. Exceptions can be made for homonyms, nomina nuda and nomina oblita, misspellings, incorrect original spellings and grammatical agreement of specific epithets. In such cases editors should use the 'notes' field to identify the change and explain their reasoning.

For unaccepted names, editors must include a statement in the 'unacceptreason' field. This statement, which explains the reason for non-acceptance of the taxon, will be displayed in brackets after the status. The word 'invalid' should not be used in this field because this term has its own meaning in bionomenclature, and is implicit from the 'unaccepted' status.

A dropdown list of the most commonly used reasons is available to encourage consistency of usage for these terms. These are listed and explained below. A reason for non-acceptance should be chosen from the available formats, if applicable, although a free text field is also provided to allow full explanation of complex cases.

\section{a. Superseded combination}

This is to be used when a species is transferred to another genus, and is also known as a new combination. The term synonym should not be used for recombinations, because it has its own specific meaning (see below). 
Further detail may be provided by using the following terms in the free text field if required.

- superseded original combination

- superseded recombination

See, e.g., http://www.marinespecies.org/aphia.php?p=taxdetails\&id=209687

\section{b. Junior homonym}

To be used to indicate the invalid status of the junior, or later established name, or in the case of simultaneous establishment, the name not given precedence by a first reviser or by an ICZN or ICN ruling.

\section{c. Junior subjective synonym}

This is to be applied as the reason for the unaccepted status for the junior, or later established, subjective synonym (a published opinion that two names apply for the same taxon). This is known as an allotypic synonym in the ICN.

\section{d. Junior objective synonym}

This can be applied to the later established name in cases where two or more scientific names have the same type material (this is known as a homotypic synonym in the ICN). For example, when two different authors name a new species based on the same specimen or in more deliberate cases, where neotypes are selected to ensure that two different nominal taxa are synonymized by anchoring to the same primary type.

\section{e. Nomen nudum}

A Latin term (meaning 'naked name') applied to those published names that do not comply with the name requirements of the codes, e.g. lack of a description or diagnosis (see ICZN glossary). Nomina $n u d a$ are not available names, and therefore an identical name may be made available later for the same or a different concept. This can be used when the taxon is indicated as a nomen nudum in a revisionary work (which is then linked as the 'status source'), but it may also be used when an editor discovers a name with such status. If this status is not yet published, then the editor should add a clear 'status note' to explain the problem.

\section{f. Nomen oblitum}

A Latin term (meaning 'forgotten name') applied after 1 January 2000 to a name, unused since 1899, which as a result of an action taken under ICZN Article 23.9.2 does not take precedence over a younger synonym or homonym in prevailing usage; the younger name which takes precedence over the nomen oblitum may be called a nomen protectum (meaning 'protected name'). The term nomen oblitum was also applied to a disused senior synonym rejected between 6 November 1961 and 1 January 1973 under ICZN Article 23b of the Code editions then in force (see ICZN Article 23.12.2). Nomina oblita remain available names; see ICZN Articles 23.9 and 23.12 for conditions controlling their use as valid names. See example here: $\mathrm{http} / /$ www.marinespecies.org/aphia.php?p=taxdetails\&id=541681

\section{Spelling variations}

There is a thorough discussion of "How is the name correctly spelled?" in Welter-Schultes (2012), and editors are strongly encouraged to read section 8 of those guidelines. Some sections are modified and included here to indicate how those guidelines should be applied to editing taxa in WoRMS.

WoRMS editors should always verify the correct spelling of any names used. As noted in WelterSchultes (2012) "In many cases spellings are not consistent with the original spellings, but appear in a slightly modified form. Often these modified spellings are correct (justified emendations), but in other 
cases they turn out to be incorrect and not in accordance with the original description and the rules of nomenclature (unjustified emendations). In most cases it is convenient to use the correct original spelling for a name, especially if names are not very commonly used". In such cases of unjustified emendations it is therefore recommended that the editor use the correct original spelling for the accepted name, particularly where the name has been used in very few publications, and is therefore not in prevailing use.

\section{g. Incorrect original spelling}

Corrections to an incorrect original spelling are classed by the ICZN as a justified emendation and the ICZN rules and recommendations must be followed (see section 8 in Welter-Schultes 2012). If a correction to an accepted name has been made under the provisions of ICZN Article 32.5, the corrected form is added to the database as 'accepted'. The original incorrect spelling is an unavailable name and should be entered in WoRMS with status 'unaccepted' and the reason for non-acceptance as 'unavailable name: incorrect original spelling'. It is left at the discretion of the editor whether or not to include original names with hyphens/diacritical marks or specific names with upper case initial letters.

\section{h. Incorrect subsequent spelling}

An 'incorrect subsequent spelling' is either a misspelling (also known as a lapsus calami or denoted 'sic' in the published literature), or an unjustified emendation (a deliberately different spelling with an explicit statement of intention or having cited both the original and the changed spellings, see ICZN Article 33.2).

\section{i. Misspelling}

Misspellings may be entered in WoRMS for erroneous names in the literature that need to be captured, e.g., when they are widespread (e.g,. Arca noe for Arca noae), or when they are needed in the database as parents for species names introduced in combination with a misspelled genus name (when the record must appear exactly as published).

Misspellings should be entered into WoRMS without an authority and with the status 'unaccepted'. The term 'misspelling' (or 'misspelling of Genus species Author, date') should be used as the reason for nonacceptance. The publication containing the misspelling should be linked to this unaccepted taxon as a source 'basis of record' and not as 'original description'. Misspelled names should link to the correctly spelled name, which may not necessarily be the accepted name.

See, e.g., http://www.marinespecies.org/aphia.php?p=taxdetails\&id=381235

\section{j. Unjustified emendation}

Unjustified emendations are nomenclatural acts under ICZN article 33.2 and must strictly be a 'demonstrably intentional change' of the original spelling. Cases where both the original spelling and the changed spelling are cited, with the latter used as valid, are unjustified emendations, and therefore become available names. Unjustified emendations take as authority the author of the emendation. The term 'unjustified emendation of Genus species Author, date' should be added as free text as the reason for non-acceptance, with the source linked as 'original description' (since unjustified emendations are available names). When only the changed spelling is given, and an intention is not explicit, the name should be treated as a misspelling.

\section{k. Incorrect grammatical agreement of specific epithet}

To be used in the case of mandatory changes in spelling consequent upon changes in rank or combination. See Welter-Schultes (2012) section 8.1.6 on gender agreement, which contains a comprehensive discussion on this topic. If a correction has been made to an accepted name under the provisions 
of ICZN Article 34, which covers gender agreement or a change of suffix with change of rank, the corrected form is to be listed as 'accepted' with an appropriate source linked. The original name with the wrong gender agreement should be added to the database with status 'unaccepted' and reason for nonacceptance 'incorrect grammatical agreement of specific epithet'. Editors are encouraged to introduce correct spellings as new, accepted taxa when such errors are spotted (in accepted names only, superseded combinations should be written as encountered and should not be corrected). A 'Nomenclature note' should be added to explain that this is the first time the correct spelling is used. See example here: http://www.marinespecies.org/aphia.php?p=taxdetails\&id=103195

\section{l. Misapplication}

There are many examples in taxonomic nomenclature when an accepted name has been misapplied to an incorrectly identified specimen. Such misapplications of the name (also known as misidentifications) are, in WoRMS, referred to as misapplications.

Misapplications are not nomenclatural acts and therefore do not need to be systematically entered in synonymy lists. They need only be entered in the database when one or more of the following conditions is met:

- The misapplication is given in an influential textbook or identification guide and has initiated an incorrect usage in many subsequent works.

- The misapplication leads to species being recorded outside their known geographical area.

- The misapplication has been unduly treated as a separately available name (i.e., with separate authorship and as an apparent homonym of the original name) by later authors.

- The misidentified specimen has been explicitly cited as a basis for the description of a subsequently available name.

- The misapplication is involved in the typification of a genus so as to become relevant under ICZN Article 69.2 .3 or 70.3 (but note that a misapplication explicitly applied as type of a new genus is a nomenclatural act under ICZN Article 67.13).

Misapplications need a separate entry, distinct from the correctly identified 'Genus species Author, date', because they link to a different accepted name. The format for such cases should be:

Genus species Author, date sensu Author of misapplication, date

The reason for non-acceptance field should contain 'misapplication'. For an example of this and how to represent it in WoRMS see:

http://www.marinespecies.org/amphipoda/aphia.php?p=taxdetails\&id=510827

\section{m. Unavailable names}

In addition to those already mentioned, there are numerous complex reasons for a name to be unavailable, therefore a free text field is provided for use in these cases.

Some examples of such usages are given below:

- published as 'variety' or 'form' after 1960 (ICZN 15.2).

http://www.marinespecies.org/aphia.php? $\mathrm{p}=$ taxdetails\&id $=758580$

- placed on the Official Index by ICZN Opinion \#

http://www.marinespecies.org/aphia.php?p=taxdetails\&id=266910

Editors can use the search function to see how other similar entries have been made in WoRMS by typing, e.g., 'ICZN Opinion' in the 'unacceptreason contains' field on the Aphia taxon search page. 


\section{n. Interim unpublished}

The definition of this is "an as yet unavailable name (until in a print issue), which has been published online only, in a work that does not show evidence of ZooBank registration (ICZN Article 8.5)". This status is only needed for taxa published according to the ICZN and is not applicable to ICN governed taxa. A major difference in the implementation of electronic-only publication in the nomenclatural codes is that in zoology (ICZN), this must be accompanied by registration in ZooBank, while for algae, fungi and plants (ICN), it is considered just another publication type and is not necessarily linked to registration (fungal names, however, must be registered to be validly published) (Nicolson et al. 2017). This status is needed in WoRMS because some print journals publishing taxonomy make articles containing new taxa available online well before appearance of the print copy. These have delays of up to a year before being assigned to a journal issue and being printed, thus becoming conventionally ICZN print published, and making the names available under the provisions of the ICZN. Names published in these advanced versions of articles that were not registered in ZooBank are unavailable according to ICZN regulations, until a version (online or print) that satisfies the requirements of the Code is published. Such names should be entered to WoRMS with the reason for non-acceptance as 'interim unpublished', and they will not point to an accepted name. These names can be monitored and when they are validly published, they can be changed to 'accepted' and be linked to the ICZN-compliant version of the respective work.

When editors add the publication containing the original description, it should be added with the date of the print edition, but the date of publication of the online edition should also be included as a note, so users can see that there is no oversight from the part of the editor, e.g., Neopycnodonte zibrowii Gofas, Salas \& Taviani in Wisshak, López Correa, Gofas, Salas, Taviani, Jakobsen \& Freiwald, 2009. The source states: Deep Sea Research I 56 (3): 374-404 [published online 29 October 2008; printed edition of the journal dated March 2009].

See an example here: http://www.marinespecies.org/aphia.php?p=sourcedetails\&id=126164

\section{Temporary name}

This name status can be used to create ad-hoc higher rank taxa of convenience to accommodate child taxa for which the classification is not yet finalised. This is usually applied to family and generic names. If, for example, there is a taxon (any rank) that does not fit in the current classification, the editor can create a temporary name ' $\mathrm{X}$ incertae sedis', where ' $\mathrm{X}$ ' is the name of the parent taxon. There are many examples of this usage within WoRMS, see, e.g., Lysianassoidea incertae sedis. Incertae sedis means 'of an uncertain seat'; and should be applied only to taxa of uncertain systematic position. When editors create these names, the status 'Temporary name' should be applied and the placement of taxa within this category should, whenever possible, be backed up with a 'status source'.

In some cases, placeholder names may be used to indicate that we know which clade a taxon belongs to in the phylogeny and we also know that it does not belong to the crown group. These can be represented using [unassigned] in front of the taxon name, see an example here:

http://www.marinespecies.org/aphia.php?p=taxdetails\&id=382219

Temporary names can also be used as a way to record unnamed cryptic species in WoRMS. In many cases there is a considerable time lag between discovery of cryptic species (e.g., during phylogeographic or barcoding studies) and their formal taxonomic description. Informal names, which are attributed to individual cryptic clades, are sometimes used again in subsequent papers. These names thus become unofficial names for the taxa involved. When this occurs over an extended interval, it may be desirable to record these names in WoRMS. An excellent example for such a case is the tropical sea urchin genus Echinometra, which contains six accepted, formally described extant species, and several yet unnamed cryptic species. These were discovered by cross-fertilization experiments in the 1980s 
(Uehara \& Shingaki 1985), and confirmed by genetic studies (Matsuoka \& Hatanaka 1991; McCartney et al. 2000). Formal descriptions, however, are still missing, in part because the relationship between the four cryptic species and available historical taxon names is not well understood. The informal names Echinometra sp. A, and Echinometra sp. C, established in one of the first papers dealing with the subject, are widely used (and consistently applied) by the scientific community and, therefore, have been captured in WoRMS (http://www.marinespecies.org/echinoidea/aphia.php?p=taxdetails\&id=994686; http://www.marinespecies.org/echinoidea/aphia.php?p=taxdetails\&id=994687).

\section{Uncertain name}

This status is used to indicate taxonomic or nomenclatural uncertainty for cases that cannot be classed as either 'accepted' or 'unaccepted'. In WoRMS, an unaccepted name must point to a currently accepted name. Uncertain names, however, commonly do not point to an accepted name and the editor should contact the Data Management Team to have this name entered without linking to an accepted name. For uncertain names, editors must include a statement of the reason for non-acceptance. There are three options available for uncertain names to encourage consistency of usage for these terms. These are listed and explained below.

\section{a. Nomen dubium}

A Latin term (meaning 'doubtful name') which is used to refer to a name of unknown or doubtful application. This applies to a name which is available (animals) or validly published (plants, algae and fungi) but of uncertain taxonomic significance despite the attention given, usually, for example, because types have been lost (or are poorly preserved), or if the description does not allow us to know with certainty which species was really meant. Nomen dubium should only be used when given this status in a revisionary work, not when an editor deems it so, and it should be supported by the source flagged as 'status source'. See here: http://www.marinespecies.org/aphia.php?p=taxdetails\&id=851739

If an editor has doubts about a name in recent use that has not been stated in the literature to be a nomen dubium, a note could be added to the name but it must remain 'accepted'. See here: http://www.marinespecies.org/aphia.php? $\mathrm{p}=$ taxdetails\&id=391348;

http://www.marinespecies.org/aphia.php?p=taxdetails\&id=737113

\section{b. Taxon inquirendum}

A taxon may be of uncertain taxonomic significance because it has not been revised nor used in the recent literature; contrary to the nomen dubium which resists revision because the supporting data are deficient, the taxa treated as inquirenda may still have extant type specimens or be adequately described, but just not have been reassessed; their generic assignment may be outdated, and they may be overlooked synonyms of valid names. This uncertain status should have a 'status note' added as explanation, and should preferably only be used when given this status in a revisionary work, not when an editor deems it so. The information should be supported by a source flagged as 'status source'. See here: http://www.marinespecies.org/aphia.php?p=taxdetails\&id=711728

\section{c. Unassessed}

This is used to refer to names coming from nomenclators (lists of names) or from, e.g., museum collection databases, where the status might be known in the published literature, but for which the status has not yet been researched, assessed and documented in WoRMS by a taxonomic editor. When such lists are integrated into WoRMS, the names should be labelled as 'unassessed'. For these names, the priority will be to assess their current status and to document this with an appropriate source flagged as 'status source'. 


\section{Alternate representation}

This is any combination that appears in the literature, is distinct from the 'accepted name', but is not currently wrong or unaccepted. Alternate representation can be used to deal with contradictory taxonomic treatments. One of the names must be 'accepted' but the alternative treatment may be stated as 'alternate representation' instead of 'unaccepted'.

Another use for this status is to deal with subgenera, subfamilies, etc. Names of species with an interpolated subgenus name - Genus (Subgenus) species - may be given the status of 'alternate representation' to the 'accepted' plain binomen Genus species.

See, e.g., http://marinespecies.org/aphia.php?p=taxdetails\&id=138995

This can be extended to the situation where the subgenus is raised to genus status, but where there is, as yet, no consensus in the literature (then Subgenus species is also 'alternate representation' to Genus species). When a consensus emerges or when a definitive revision is published, one of the alternate representations should become 'unaccepted' and the other one 'accepted'.

\section{Problematic entries}

\section{Linking an unaccepted name to more than one taxon}

It often happens that a higher taxon becomes unaccepted and its 'children' are spread over several other taxa. In a taxonomic publication, this is represented by 'in part' or 'Pro parte'. It is not possible to represent this in WoRMS, since this makes the database structure highly complex. In such cases, editors can contact the Database Management Team to arrange to have no accepted name, and should add a clear taxonomic remark note. See an example here: http://www.marinespecies.org/aphia.php?p=taxdetails\&id=106675

\section{Authorities}

The International Plant Names Index (IPNI) has a standardised list of authors and their abbreviations (with strong recommendations to use these). Authors of plant, algal and fungal taxa should be cited following the standard form indicated in http://www.ipni.org/ipni/authorsearchpage.do.

The ICZN Code does not provide an official guide for the name of the author. According to WelterSchultes (2012), researchers should use the authority as written in the publication, we advise editors to follow this recommendation. In accordance with ICZN Art. 50.1, where the authority of a taxon differs from the author(s) listed on a publication, editors should use the following format: "Author 1 in Author 2, Date'.

Authors of zoological names are usually cited without their initials. In some cases, when more than one homonymous author is active within the same taxon on overlapping dates, they can be cited using the format 'E.A. Smith'. If these authors also have the same initials, use as many letters of the first name as needed to discriminate them (e.g., Ev. Marcus/Er. Marcus, Ant. Bivona/And. Bivona). In case of doubt, editors can check the current usage in WoRMS with an authority search.

\section{Nomen protectum}

A Latin term (meaning 'protected name') applied to a name that has been given precedence over its unused senior synonym or senior homonym relegated to the status of nomen oblitum (see ICZN Article 23.9.2). If this status is given to a name in the literature, then a 'status note' should be written detailing the information regarding the case and backed up by the 'status source'. A nomen protectum is protected against an older synonym or homonym but can become unaccepted 
(e.g., by further synonymy with another name than the corresponding nomen oblitum). See here: http://www.marinespecies.org/aphia.php?p=taxdetails\&id=540396

\section{Source categories}

When a source (reference/publication) is linked to a taxon, a relevant source category must be chosen. The addition of certain sources such as 'Original description', 'New combination reference' or 'Status source', are necessary, but further choice of sources under a species entry is at the discretion of the editor. Some common species trigger a large literature and the editor should select the most relevant sources. Sources providing only the species name in a regional checklist or database should not be linked to the taxon name, but as a source for the corresponding 'Distribution' entry.

The following source categories (in alphabetical order) are available:

\section{a. Additional source}

This can be used for any publication that contains additional information about the present taxon, which cannot be categorised as another source category.

\section{b. Basis of record}

This is the default category for the source which has triggered the entry in WoRMS, either as an accepted name or an unaccepted name. Unavailable (unaccepted) names (e.g., nomina nuda; misspellings, misapplications) to which 'original description' cannot apply will also use this source category.

\section{c. Biology source}

A publication that gives information about the biology or natural history of the present taxon, e.g., morphology, feeding, growth, reproduction, etc.

\section{d. Classification source}

This should be used for publications that contain information about the classification of the present taxon. It can relate to the phylogenetic classification of a taxon and encompasses both molecular and morphological approaches.

\section{e. Context source}

A publication that is used to link a taxon to a geographic context (e.g., the European Register of Marine Species), or to a thematic context (sub-collection) of Aphia, e.g., to a thematic species database (TSD) such as the World Register of Deep-Sea Species (WoRDSS).

\section{f. Ecology source}

A publication that gives information about the relations and interactions between the present taxon and its environment, including other organisms.

\section{g. Identification resource}

This can be applied to papers or websites which include keys to species in a genus, genera in a family or a more general identification guide. The usage will vary across taxa.

\section{h. New combination reference}

This should be used to indicate the first source to propose the new combination; for animals this is often difficult to trace and not explicit, except in recent publications; for botanical names the author of this source is part of the authority cited with the valid name. The new combination reference should be linked to the unaccepted name and will then also be visible on the accepted name page. In cases where the new combination is implied by a published work, but the taxon is not specifically mentioned (e.g., if a subgenus is raised to genus status or sinking a species-rich genus into another), the included species 
should be combined accordingly in their 'accepted' name. In these cases, a 'Taxonomic remark' such as: "New combination herein, to be consistent with synonymisation of [genus 1] with [genus 2] by [author, year]", should be added by the editor.

\section{i. Original description}

This is the publication in which the nominal taxon was originally described. Original description sources should be added to the 'original name' (not to recombinations) and tagged as 'Original description' using the source drop-down menu. Page references are not needed where a paper is entirely dedicated to the description of the referred taxon, but they are useful additions in larger works. Ideally, the page field should contain the interval of pages dealing with the taxon, as well as the reference to plates if these are separate from the text, and may include references to text-figures as well.

\section{j. Original description (unavailable nomenclaturally)}

This source category is intended for cases (common in the $17^{\text {th }}$ and early $18^{\text {th }}$ century) where names were made available in a binominal work by a mere reference to an earlier source (e.g., pre-Linnean, or rejected) where the species is figured and described (see ICZN art. 12.2.1). In those cases, this earlier source should be linked as: 'Original description (unavailable nomenclaturally)'. This can also be used more generally for sources where new taxa were proposed but failed to fulfil the conditions for availability (e.g., varieties for animals after 1960; species described without a type after 1999), where the conditions for availability were fulfilled later.

\section{k. Redescription}

This is a publication in which the present taxon is redescribed.

\section{l. Source of synonymy}

This should be used for those publications that contain information on the synonymy of a taxon (i.e., where one taxon is declared a junior subjective synonym of another). It should not be used to indicate those papers from which a 'full synonymy' listing has been taken. It should not be confused with 'New combination reference'.

\section{m. Status source}

This is used for a publication in which the current status of the taxon is confirmed as valid, or pulled out of synonymy, or stated as 'nomen dubium' or 'taxon inquirendum', after a revision. At supraspecific level it may refer to a source where the taxon was assigned a particular rank (e.g., subfamily to family). ICZN Opinions are treated as regular papers and cited as 'Status source' for the taxa they rule on. For downgrading to a junior synonym 'Source of synonymy' is used instead. For transfers to another genus 'New combination reference' is used.

\section{n. Subsequent type designation}

This is used for a publication in which the type species or type specimen of the nominal taxon was designated. This source is needed at the genus level when the type species field indicates 'subsequent designation'. At the species level it would record any lectotype or neotype designation.

\section{o. Toxicology source}

This source category is used in the IOC-UNESCO Taxonomic Reference List of Harmful Micro Algae (http://www.marinespecies.org/hab/) and indicates a publication that contains information on the toxic nature of the present taxon. 


\section{Note categories}

Where further information needs to be provided for clarification, a variety of notes are available to the editor. If the information is related to a particular linked source, then it is recommended that the note be attached to the source itself. When adding a note, the editor can also link a source to back up the note, which is then visible when clicking on the details tab. The following note categories (in alphabetical order) remain for narrative text that should be visibly associated with the taxon:

\section{a. Altitude}

This note is for recording the altitude of a taxon. It is only used in certain Global Species Databases which include non-marine taxa, e.g., MolluscaBase, or amphidromous and diadromous species that enter rivers, or landlocked populations in lakes, e.g., FishBase.

\section{b. Depth}

This note is for recording a depth record or depth range of a taxon.

\section{c. Description}

This note allows editors to input diagnoses for taxa.

\section{d. Distribution}

This note is for any additional information on the distribution of a taxon that is not placed in the distribution module.

\section{e. Etymology}

This note allows editors to input information regarding the etymology of a name.

\section{f. Fossil range}

This note is for additional narrative information concerning the fossil range of a taxon; referring to presence in specific time intervals.

\section{g. LSID}

This is a place to provide a link to another database where Life-Science Identifiers (LSIDs) are used.

\section{h. Miscellaneous}

This note is for additional narrative information that does not fit in any of the other categories.

\section{i. Nomenclature}

This note is for additional narrative information about the nomenclature of a taxon. It can include information on, e.g., original spellings and misspellings, homonymy, grammatical gender, authority and publication date, etc.

\section{j. Stratigraphy}

This note is for additional narrative information concerning the stratigraphy (presence of fossil taxa in particular rock units).

\section{k. Status}

This note category should be used to provide additional information regarding the status of a nominal taxon, for example, where it has been indicated in the literature as, e.g., nomen protectum, taxon inquirendum, nomen dubium, or has been suppressed or conserved by an ICZN Opinion, etc. 


\section{Type material}

This note can be used to cover all narrative information regarding the type material of a nominal taxon, including notes on holotype, syntype, paratype, neotype and lectotype specimens, type designation, and museum deposition information.

\section{m. Type species}

This note is for additional narrative information about the designation of type species that is not possible to indicate in the type species field.

\section{n. Type locality}

This note is for additional narrative information about the type locality of a taxon, e.g. an incorrectly spelled or ambiguous type-locality descriptor could be input here.

\section{o. Taxonomic remark}

This note is for any additional taxonomic remarks on a taxon. It can include information on synonymy, new combinations, classification and identification.

\section{Entering type material and type locality data}

It is important to clarify here the difference between a type locality and a distribution.

The type locality is a unique locality (more rarely localities) associated with the holotype, syntypes, neotype or lectotype of an available species-group name. A distribution is a property of a taxon and synthesises the type localities of all its synonyms and all published records.

The type locality can be defined as the geographical and stratigraphical attributes of the name-bearing type(s) stated when a new species is described. It is considered as specimen-related data. It is therefore strongly recommended that type material data (e.g., institution/collection, registration number, nature of type) and type locality data (e.g., latitude, longitude, depth, date) are entered using the specimen module. All data concerning name-bearing types should be entered in association with the original name in WoRMS, not with a recombination. The information will then be automatically associated with all names linked to this original name. Type localities should be entered as close to verbatim as possible from the original publication providing all available details, e.g., geographical place name, depth, latitude, longitude. The type locality entry must be based on its original literature source, which should be linked accordingly.

Type locality may change over time, being restricted by lectotype designation or superseded by neotype designation or ICZN opinion. In these cases, further literature sources can be linked to these changes (in the appropriate field in the specimen module). See an example for a neotype entry here: http://www.marinespecies.org/aphia.php?p=specdetails\&id=67634\&tid=124332

The online input interface offers the option to enter coordinates for type localities in degrees-minutesseconds, which are then re-calculated to decimal degrees. When editors enter decimal degrees, they need to be aware of the use of the minus-sign and use it appropriately (East and North = '+'; West and South $\left.={ }^{\prime} \cdot{ }^{`}\right)$.

\section{Environment}

It is now mandatory when adding a new taxon to indicate the environment of the taxon. If the name has already been created, editors can add this information retrospectively. In WoRMS, four flags are available (Marine, Freshwater, Brackish, Terrestrial) and any combination of these can be checked. Each flag has three options (Yes, No and Unknown). 
As a default, the database shows only marine and/or brackish water species based on the environment flags (where marine = 'Yes' or 'Unknown' and/or brackish = 'Yes' or 'Unknown'). Therefore, to ensure that pure freshwater and terrestrial species are not shown on WoRMS, it is important that 'No' is checked for both the marine and brackish environment boxes.

The generally agreed definitions are:

- Freshwater: species occur at a salinity range of $0-0.5 \mathrm{ppt}$

- Brackish water: species occur at a salinity range of 0.5-30 ppt

- Marine: species occur at salinities higher than $30 \mathrm{ppt}$

Further distinctions of salinities (e.g., oligohaline (0.5-5 ppt), mesohaline (5-18 ppt) and polyhaline $(18-30 \mathrm{ppt}))$, can be added in a note on the taxon page, if needed.

When entering more difficult-to-define environments such as for those species inhabiting strandline habitats, which flags should be checked? Some groups have chosen terrestrial only for such species. In the World Amphipoda Database, this was agreed as follows: 'beach hoppers' (Talitridae) recorded in the marine environment should be flagged 'marine only' as they depend on the marine environment. 'Land hoppers' should be flagged 'terrestrial only' as they occur away from marine or freshwater sources and 'freshwater hoppers' should be flagged 'freshwater only' as they are recorded, e.g., on the beaches of lakes and rivers and therefore depend on the freshwater environment. Other taxonomic group editors may choose to combine environment flags, e.g., insects and birds. For seabirds, both marine and terrestrial are checked, as all seabirds also depend on the land for reproduction. Similarly, both 'marine' and 'terrestrial' flags are checked for certain insects that live on land but are truly dependent on the marine environment for at least part of their life cycle. For freshwater species, similar combinations of 'fresh' and 'terrestrial' can be made. For anadromous/catadromous fish, both 'marine' and 'fresh' may be checked. It is important that editors use these flags consistently within a taxon.

\section{Higher classification}

A higher level classification of all living organisms was published by Ruggiero et al. (2015). This paper provides a management classification for all living organisms and will form the basis for the Catalogue of Life higher classification. A comparison between this paper and the higher classification in WoRMS is being made. Where inconsistencies appear, the DMT consults with the responsible editors to discuss if changes are needed. WoRMS aims to reflect current knowledge and therefore will allow newer publications to be applied to higher level taxa if the editor deems it necessary and scientific consensus has been reached. If no editor is available for a group, the classification by Ruggiero et al. (2015) will be followed. Ruggiero et al. (2015) cover the classification from superkingdom to order level. Below the rank of order (e.g., suborder, infraorder, parvorder, superfamily, family, subfamily, genus) the classification is the responsibility of the editor of the taxon.

Decisions about making changes at these levels may await scientific consensus if there is dispute or the editor is uncertain of the validity of the proposed changes. In such cases it is recommended that the editor add a 'Taxonomic remark' note indicating that the classification is currently under scrutiny and providing one or more 'Classification source' links to the relevant scientific literature for the user. An editor may also contact the Catalogue of Life team for further discussion to update the management hierarchy.

\section{Conclusion}

WoRMS has now existed for a decade and has been edited by more than 300 taxonomic experts during this period. Naturally, it could not be foreseen from the start how the data would be entered, which types of data would be needed and how best to ensure consistency. Experience has shown that researchers 
working with different groups of organisms follow different traditions for handling taxonomic data. Differences exist not only between, e.g., botanists and zoologists, but also at the lower taxonomic level. Where no guidance existed, editors have found their own way of doing things, which has resulted in the proliferation of a confusing variety of terms, each of them well motivated but essentially similar to others. The need for standardisation has become apparent in recent years and has now led to the restriction of data field inputs to a choice of pre-defined values (e.g., status of a name, reason for non-acceptance or category of source or note). This streamlining of data terms has allowed for similar meanings to be grouped. Unclear terms have been refined and clarified. At the same time, in working with such a diverse team of editors and taxa, WoRMS recognises that there will always be more complex and difficult cases and therefore strives to allow editors the freedom needed to record and explain these. Increasing usage and application of WoRMS in other taxonomic databases, institutes, museums, herbaria, environmental agencies, fisheries industry and research, clearly demonstrates its usefulness. The revised priorities for data entry and improved consistency will further strengthen its usage in the biodiversity informatics arena and places greater emphasis on the importance of expert knowledge as applied in WoRMS.

\section{Acknowledgements}

The authors would like to acknowledge the important contributions of past members of the Steering Committee and the past and present members of the WoRMS editorial board in the development of the World Register of Marine Species. The creation and continuous further development of the WoRMS database has benefited from funding from numerous projects, most recently EMODnet Biology I (MARE/2008/03-Lot 4 Biology - Contract No. SI2.531562; 2009-2011), EMODnet Biology II (MARE/2012/10 - Lot 5 Biology - Contract No. SI2.657705; 2012-2016) and LifeWatch (2012-2016). The first author (TH) is supported by the UK Natural Environment Research Council (NERC).

\section{References}

Appeltans W., Costello M.J., Vanhoorne B., Decock W., Vandepitte L., Hernandez F., Mees J. \& Vanden Berghe E. 2008. Aphia for a World Register of Marine Species (WoRMS). In: Mees J. \& Seys J. (eds) Book of Abstracts VLIZ. Young Scientists' Day, Brugge, Belgium, 29 February 2008. VLIZ Special Publication 40, Vlaams Instituut voor de Zee, Oostende, Belgium.

Appeltans W., Decock W., Vanhoorne B., Hernandez F., Bouchet P., Boxshall G., Fauchald K., Gordon D.P., Poore G.C.B., van Soest R., Stöhr S., Walter C. \& Costello M.J. 2011. The World Register of Marine Species: an authoritative, open-access web-resource for all marine species. In: Proceedings of the Future of the $21^{\text {st }}$ Century Ocean: Marine Sciences and European Research Infrastructures, an International Symposium, Brest, France, 28 June-1 July 2011. Europole Mer, Plouzané.

Appeltans W., Ahyong S.T., Anderson G., Angel M.V., Artois T., Bailly N., Bamber R., Barber A., Bartsch I., Berta A., Błażewicz-Paszkowycz M., Bock P., Boxshall G., Boyko C.B., Brandão S.N., Bray R.A., Bruce N.L., Cairns S.D., Chan T.Y., Chan L., Collins A.G., Cribb T., Curini-Galletti M., Dahdouh-Guebas F., Davie P.J.F., Dawson M.N., De Clerck O., Decock W., De Grave S., de Voogd N.J., Domning D.P., Emig C.C., Erséus C., Eschmeyer W., Fauchald K., Fautin D.G., Feist S.W., Fransen C.H.J.M., Furuya H., Garcia-Alvarez O., Gerken S., Gibson D., Gittenberger A., Gofas S., Gómez-Daglio L., Gordon D.P., Guiry M.D., Hoeksema B.W., Hopcroft R., Jaume D., Kirk P., Koedam N., Koenemann S., Kolb J.B., Kristensen R.M., Kroh A., Lambert G., Lazarus D.B., Lemaitre R., Longshaw M., Lowry J., Macpherson E., Madin L.P., Mah C., Mapstone G., McLaughlin P., Meland K.L., Messing C.G., Mills C.E., Molodtsova T.N., Mooi R., Neuhaus B., Ng P.K.L., Nielsen C., Norenburg J., Opresko D.M., Osawa M., Paulay G., Perrin W., Pilger J.F., Poore G.C.B., Pugh P., Read G.B., Reimer J.D., Rius M., Rocha R.M., Rosenberg G., Saiz-Salinas J.I., Scarabino V., Schierwater B., Schmidt-Rhaesa A., Schnabel K.E., Schotte M., Schuchert P., Schwabe E., Segers H., Self-Sullivan C., Shenkar N., Siegel V., Sterrer W., Stöhr S., Swalla B., Tasker M.L., Thuesen E.V., 
Timm T., Todaro A., Turon X., Tyler S., Uetz P., van der Land J., van Ofwegen L.P., van Soest R.W.M., Vanaverbeke J., Vanhoorne B., Walker-Smith G., Walter T.C., Warren A., Williams G., Wilson S.P., Hernandez F., Mees J., Costello M.J. 2012. The magnitude of global marine species diversity. Current Biology 22: 1-14. https://doi.org/10.1016/j.cub.2012.09.036

Bouchet P., Bary S., Heros V. \& Marani G. 2016. How many species of molluscs are there in the World's oceans, and who is going to describe them? In: Heros V., Strong E. \& Bouchet P. (eds) Tropical Deep-Sea Benthos 29: 9-24. Mémoires du Muséum national d'Histoire naturelle 208, Muséum national d'Histoire naturelle, Paris.

Boyko C.B, Bruce N.L., Hadfield K.A., Merrin K.L., Ota Y., Poore G.C.B., Taiti S., Schotte M. \& Wilson G.D.F. (eds) (2008 onwards). World Marine, Freshwater and Terrestrial Isopod Crustaceans Database. Available from http://www.marinespecies.org/isopoda/ [accessed 27 Jun. 2017].

Census/WoRMS News Release. 2008. How many fish (and other species) in the sea? Validated list of known ocean species surpasses 120,000, over halfway to goal of complete inventory by October, 2010. Census of Marine Life and World Register of Marine Species, Press Release. Available from http://www.coml.org/press-releases-2008 or http://www.marinespecies.org/news.php? $\mathrm{p}=$ show\&id=349 [accessed 28 Jun. 2017].

Costello M.J. 2000. Developing species information systems: the European Register of Marine Species. Oceanography 13 (3): 48-55. https://doi.org/10.5670/oceanog.2000.09

Costello M.J. \& Chaudhary C. Marine Biodiversity, Biogeography, Deep-Sea Gradients, and Conservation. Current Biology 27: R511-R527. https://doi.org/10.1016/j.cub.2017.04.060

Costello M.J., Bouchet P., Boxshall G., Fauchald K., Gordon D., Hoeksema B.W., Poore G.C.B., van Soest R.W.M., Stöhr S., Walter T.C., Vanhoorne B., Decock W. \& Appeltans W. 2013. Global coordination and standardisation in marine biodiversity through the World Register of Marine Species (WoRMS) and related databases. PLoS ONE 8. https://doi.org/10.1371/journal.pone.0051629

Costello M.J., Claus S., Dekeyzer S., Vandepitte L., Tuama É.Ó., Lear D. \& Tyler-Walters H. 2015. Biological and ecological traits of marine species. PeerJ 3:e1201. https://doi.org/10.7717/peerj.1201

De Broyer C., Clarke A., Koubbi P., Pakhomov E., Scott F., Vanden Berghe E. \& Danis B. (eds). 2017. Register of Antarctic Marine Species. Available from http://www.marinespecies.org/rams [accessed 27 Jun. 2017].

Garnett S.T. \& Christidis L. 2017. Taxonomy anarchy hampers conservation. Nature 546: 25-27. https://doi.org/10.1038/546025a

Hawksworth D.L. 2010. Terms Used in Bionomenclature: The Naming of Organisms (and Plant Communities). Global Biodiversity Information Facility, Copenhagen.

Available from www.gbif.org/document/80577 [accessed 19 Dec. 2017].

Horton T., Kroh A., Ahyong S., Bailly N., Boury-Esnault N., Brandão S.N., Costello M.J., Gofas S., Hernandez F., Mees J., Paulay G., Poore G.C.B., Rosenberg G., Decock W., Dekeyzer S., Lanssens T., Vandepitte L., Vanhoorne B., Verfaille K., Adlard R., Adriaens P., Agatha S., Ahn K.J., Akkari N., Alvarez B., Anderson G., Angel M., Arango C., Artois T., Atkinson S., Bank R., Barber A., Barbosa J.P., Bartsch I., Bellan-Santini D., Bernot J., Berta A., Bieler R., Blanco S., Blasco-Costa I., Blazewicz M., Bock P., Böttger-Schnack R., Bouchet P., Boxshall G., Boyko C.B., Bray R., Bruce N.L., Cairns S., Campinas Bezerra T.N., Cárdenas P., Carstens E., Chan B.K., Chan T.Y., Cheng L., Churchill M., Coleman C.O., Collins A.G., Corbari L., Cordeiro R., Cornils A., Coste M., Crandall K.A., Cribb T., Cutmore S., Dahdouh-Guebas F., Daly M., Daneliya M., Dauvin J.C., Davie P., De Broyer C., De Grave S., de Mazancourt V., de Voogd N., Decker P., Defaye D., d'Hondt J.L., Dijkstra H., Dohrmann M., Dolan J., Domning D., Downey R., Drapun I., Ector L., Eisendle-Flöckner U., Eitel M., Encarnação S.C.d., 
Enghoff H., Epler J., Ewers-Saucedo C., Faber M., Feist S., Figueroa D., Finn J., Fišer C., Fonseca G., Fordyce E., Foster W., Frank J.H., Fransen C., Furuya H., Galea H., Garcia-Alvarez O., Garic R., Gasca $\approx$ R., Gaviria-Melo S., Gerken S., Gheerardyn H., Gibson D., Gil J., Gittenberger A., Glasby C., Glover A., Gómez-Noguera S.E., González-Solís D., Gordon D., Grabowski M., Gravili C., GuerraGarcía J.M.., Guidetti R., Guilini K., Guiry M.D., Hadfield K.A., Hajdu E., Hallermann J., Hayward B., Hendrycks E., Herrera Bachiller A., Ho J.s., Høeg J., Hoeksema B., Holovachov O., Hooper J., Houart R., Hughes L., Hyžný M., Iniesta L.F.M., Iseto T., Ivanenko S., Iwataki M., Jarms G., Jaume D., Jazdzewski K., Karanovic I., Karthick B., Kim Y.H., King R., Kirk P.M., Klautau M., Kociolek J.P., Kolb J., Kotov A., Krapp-Schickel T., Kremenetskaia A., Kristensen R., Kulikovskiy M., Kullander S., La Perna R., Lambert G., Lazarus D., Le Coze F., LeCroy S., Leduc D., Lefkowitz E.J., Lemaitre R., Liu Y., Lörz A.N., Lowry J., Ludwig T., Lundholm N., Macpherson E., Madin L., Mah C., Mamos T., Manconi R., Mapstone G., Marek P.E., Marshall B., Marshall D.J., Martin P., McInnes S., Meidla T., Meland K., Merrin K., Mesibov R., Messing C., Miljutin D., Mills C., Moestrup Ø., Mokievsky V., Molodtsova T., Monniot F., Mooi R., Morandini A.C., Moreira da Rocha R., Moretzsohn F., Mortelmans J., Mortimer J., Musco L., Neubauer T.A., Neubert E., Neuhaus B., Ng P., Nguyen A.D., Nielsen C., Nishikawa T., Norenburg J., O’Hara T., Okahashi H., Opresko D., Osawa M., Ota Y., Patterson D., Paxton H., Perrier V., Perrin W., Petrescu I., Picton B., Pilger J.F., Pisera A., Polhemus D., Potapova M., Pugh P., Read G., Reimer J.D., Reip H., Reuscher M., Reynolds J.W., Rimet F., Rios P., Rius M., Rützler K., Rzhavsky A., Sabbe K., Saiz-Salinas J., Sala S., Santos S., Sar E., Sartori A.F., Satoh A., Schatz H., Schierwater B., Schmidt-Rhaesa A., Schneider S., Schönberg C., Schuchert P., Senna A.R., Serejo C., Shaik S., Shamsi S., Sharma J., Shear W.A., Shenkar N., Shinn A., Short M., Sicinski J., Siegel V., Sierwald P., Simmons E., Sinniger F., Sivell D., Sket B., Smit H., Smit N., Smol N., Souza-Filho J.F., Spelda J., Sterrer W., Stienen E., Stoev P., Stöhr S., Strand M., SuárezMorales E., Summers M., Suttle C., Swalla B.J., Taiti S., Tanaka M., Tandberg A.H., Tang D., Tasker M., Taylor J., Taylor J., Tchesunov A., ten Hove H., ter Poorten J.J., Thomas J., Thuesen E.V., Thurston M., Thuy B., Timi J.T., Timm T., Todaro A., Turon X., Tyler S., Uetz P., Utevsky S., Vacelet J., Vader W., Väinölä R., Van de Vijver B., van der Meij S.E., van Haaren T., van Soest R., Van Syoc R., Venekey V., Vonk R., Vos C., Walker-Smith G., Walter T.C., Watling L., Wayland M., Wesener T., Wetzel C., Whipps C., White K., Williams D., Williams G., Wilson R., Witkowski A., Witkowski J., Wyatt N., Wylezich C., Xu K., Yasuhara M., Zanol J., Zeidler W. 2017. World Register of Marine Species. https://doi.org/10.14284/170

ICZN, International Commission on Zoological Nomenclature. 2012. Amendment of Articles 8, 9, 10, 21 and 78 of the International Code of Zoological Nomenclature to expand and refine methods of publication. Zookeys 219: 1-10. https://doi.org/10.3897/zookeys.219.3944

International Commission on Zoological Nomenclature. 1999. International Code of Zoological Nomenclature. Fourth Edition. The International Trust for Zoological Nomenclature, London.

Available from http://www.nhm.ac.uk/hosted-sites/iczn/code/ [accessed 5 Dec. 2017].

King A.M.Q., Adams M.J., Carstens E.B. \& Lefkowitz E.J. (eds). 2012. Virus Taxonomy: Classification and Nomenclature of Viruses. Ninth Report of the International Committee on Taxonomy of Viruses. Academic Press. London.

Krell F.T. \& Pape T. 2015. Electronic publications need registration in ZooBank to be available. The Bulletin of Zoological Nomenclature 72 (3): 245-251. https://doi.org/10.21805/bzn.v72i3.a2

Matsuoka N. \& Hatanaka T. 1991. Molecular evidence for the existence of four sibling species within the sea-urchin, Echinometra mathaei in Japanese waters and their evolutionary relationships. Zoological Science 8: 121-133. https://doi.org/10.2108/zsj.21.1057 
HORTON T. et al., Best practice guidelines for WoRMS taxonomic editors

McCartney M.A., Keller G. \& Lessios H.A. 2000. Dispersal barriers in tropical oceans and speciation in Atlantic and eastern Pacific sea urchins of the genus Echinometra. Molecular Ecology 9: 1391-1400. https://doi.org/10.1046/j.1365-294x.2000.01022.x

McNeill J. et al. eds. 2012. International Code of Nomenclature for algae, fungi, and plants (Melbourne Code), Adopted by the Eighteenth International Botanical Congress Melbourne, Australia, July 2011 (electronic ed.). Bratislava: International Association for Plant Taxonomy.

Mora C., Tittensor D.P., Adl S., Simpson A.G.B. \& Worm B. 2011. How many species are there on Earth and in the ocean? PLoS Biol 9(8): e1001127. https://doi.org/10.1371/journal.pbio.1001127

Nicolson N., Challis K., Tucker A. \& Knapp S. 2017. Impact of e-publication changes in the International Code of Nomenclature for algae, fungi and plants (Melbourne Code, 2012) - did we need to "run for our lives"? BMC Evolutionary Biology 17: 116. https://doi.org/10.1186/s12862-017-0961-8

Parker C.T., Tindall B.J. \& Garrity G.M. 2015. International Code of Nomenclature of Prokaryotes. International Journal of Systematic and Evolutionary Microbiology. https://doi.org/10.1099/ijsem.0.000778

Polaszek A., Alonso-Zarazaga M.A., Bouchet P., Brothers D.J., Evenhuis N.L., Krell F.T., Lyal C.H.C., Minell A., Pyle R.L., Robinson N.J., Thompson F.C. \& van Tol J. 2005. ZooBank: the open-access register for zoological taxonomy. Technical discussion paper. Bulletin of Zoological Nomenclature 62 (4): 210-220.

Poore G.C.B., Avery L., Błażewicz-Paszkowycz M., Browne J., Bruce N.L., Gerken S., Woolley S. 2014. Invertebrate diversity of the unexplored marine western margin of Australia: taxonomy and implications for global biodiversity. Marine Biodiversity 45 (2): 271-286.

https://doi.org/10.1007/s12526-014-0255-y

Pyle R.L. \& Michel E. 2008. ZooBank: developing a nomenclatural tool for unifying 250 years of biological information. Zootaxa 1950: 39-50.

Rees T., Vandepitte L., Decock W. \& Vanhoorne B. 2017. IRMNG 2006-2016: 10 years of a global Taxonomic Database. Biodiversity Informatics 12: 1-44. https://doi.org/10.17161/bi.v12i0.6522

Ruggiero M.A., Gordon D.P., Orrell T.M., Bailly N., Bourgoin T., Brusca R.C., Cavalier-Smith T., Guiry M.D. \& Kirk P.M. 2015. A higher level classification of all living organisms. PLoS ONE 10 (4): e0119248. https://doi.org/10.1371/journal.pone.0119248

Stöhr S., O’Hara T. \& Thuy B. (eds). 2017. World Ophiuroidea Database. Available from http://www.marinespecies.org/ophiuroidea [accessed 27 Jun. 2017].

Uehara T. \& Shingaki M. 1985. Taxonomic studies on the four types of sea urchin, Echinometra mathaei from Okinawa, Japan. Zoological Science 2: 1009.

Vandepitte L., Vanhoorne B., Decock W., Dekeyzer S., Trias Verbeeck A., Bovit L., Hernandez F. \& Mees J. 2015. How Aphia - the platform behind several online and taxonomically oriented databasescan serve both the taxonomic community and the field of biodiversity informatics. Journal of Marine Science Engineering 3: 1448-1473. https://doi.org/10.3390/jmse3041448

Vanhoorne B., Deneudt K., Appeltans W., Hernandez F. \& Mees J. 2008. The Aphia Taxon Match tool, an online quality control tool for checking your biological data against the World and European Registers of Marine Species. In: Sissy I., Maillard C. \& Tosello V. (eds). Proceedings of the International Marine Data and Information Systems Conference IMDIS-2008, Athens, Greece, 31 March-2 April 2008. IOC Workshop Report No. 219, Paris. 
Welter-Schultes F.W. 2012. Guidelines for the Capture and Management of Digital Zoological Names Information. Version 1.1 released on March 2013. Global Biodiversity Information Facility, Copenhagen. Available from http://www.gbif.org/document/80625 [accessed 5 Dec. 2017].

Manuscript received: 8 March 2017

Manuscript accepted: 18 July 2017

Published on: 28 December 2017

Topic editor: Koen Martens

Desk editor: Kristiaan Hoedemakers

Printed versions of all papers are also deposited in the libraries of the institutes that are members of the EJT consortium: Muséum national d'Histoire naturelle, Paris, France; Botanic Garden Meise, Belgium; Royal Museum for Central Africa, Tervuren, Belgium; Natural History Museum, London, United Kingdom; Royal Belgian Institute of Natural Sciences, Brussels, Belgium; Natural History Museum of Denmark, Copenhagen, Denmark; Naturalis Biodiversity Center, Leiden, the Netherlands; Museo Nacional de Ciencias Naturales-CSIC, Madrid, Spain; Real Jardín Botánico de Madrid CSIC, Spain. 